\title{
Characterization of charcoal produced from different Pyrolyzing techniques
}

\author{
Ma. Grace Curay ${ }^{1 *}$, Abigail Joy Ching', Kazel Duran', Regine Mary Talingting' $^{\prime}$ \\ and Sheila Balladares
}

\begin{abstract}
Submitted: 12 October 2019 | Accepted: 09 June 2020

Different pyrolyzing techniques are assumed to yield products with different content and adsorption rate. This study aimed to characterize five coconut charcoal samples from different pyrolyzing techniques such as Drum Kiln, Pit Method, Top Lift Updraft Method for TLUD - Top Sample \& TLUD - Bottom Sample, and Hookway Retort to determine the best production method that will yield a quality of charcoal suitable for adsorption applications. Proximate analysis and adsorption kinetic studies were done to characterize and determine the rate of adsorption. Charcoal samples were ranked based on the following criteria and weights: $70 \%$ for adsorption capacity, $20 \%$ for fixed carbon, and $10 \%$ for the volatile matter. High adsorption capacity, high fixed carbon, and low volatile matter are good charcoal qualities for adsorption. For proximate analysis, ASTM Methods (ASTM D3302, ASTM D3175-17, ASTM D3174-12, ASTM D3172-13) were used. Experimental data showed that fixed carbon content of charcoal samples from Drum Kiln, Pit Method, TLUD-Top, TLUD-Bottom, and Hookway was 54.63\%, 56.84\%, 64.77\%, 45.85\%, and $56.59 \%$ respectively; while $30.69 \%, 31.65 \%, 20.65 \%, 43.39 \%$, and $24.13 \%$ respectively for the volatile matter. For adsorption kinetic studies, optimization was done using Box-Behnken design with initial concentration, adsorbent dose, and $\mathrm{pH}$ as factors. The Hookway sample was subjected to optimization, where its optimum conditions were used for the rest of the charcoal samples. The experimental data for the adsorption kinetic studies showed that the pseudo-second-order exhibited the best fit for all the charcoal samples. The coefficient of determination for charcoal samples from Drum Kiln, Pit Method, TLUD-Top, TLUD-Bottom, and Hookway Method are $0.9253,0.944,0.7267,0.9885$, and 0.9216. Applying the weights, the best charcoal sample is from Kiln, followed by Pit, TLUD-Bottom, TLUD-Top, and Hookway. Production temperature, pressure, and humidity could be employed in future studies to determine what affects the quality of charcoal during pyrolysis.
\end{abstract}

Keywords: Proximate Analysis, adsorption kinetic, charcoal, pyrolyzing methods

${ }^{1}$ Department of Environmental Engineering, University of the Philippines, Diliman, Quezon City, Manila, 1101 Philippines

*Corresponding Author. Address: Department of Agricultural Engineering, Visayas State University, Baybay City, Leyte6521 Philippines; Email: grace.curay@vsu.edu.ph

DOI: $10.32945 /$ atr42210.2020 


\section{INTRODUCTION}

Pyrolysis is a form of thermochemical treatment of organic or carbon-based products. The material is subjected to high temperature, which then undergoes chemical and physical decomposition in the absence of oxygen. Unlike combustion and gasification processes, which involve partial or complete oxidation of the material, pyrolysis is based on heating products in the absence of air, making it a mostly endothermic process that allows for the maintaining of the high energy content of the products.

The products of pyrolysis are charcoal, tar, moisture, and gases. Charcoal can be used as activated carbon (diverse adsorbent) and has many applications such as for air purification, purification of contaminated water, teeth whitening, antiaging and digestive cleansing.

This study has the following objectives: To compare the characteristics of coconut charcoals produced from different pyrolyzing methods (Drum Kiln, Pit Method, Top Lift Updraft Method - Top, Top Lift Updraft Method - Bottom, and Hookway Method) using the following parameters: a. Proximate Analysis: Fixed Carbon, Moisture Content, Ash Content, Volatile Matter; b. Methylene Blue Number; and c. Adsorption Kinetic Studies; To determine the rate of adsorption and mechanism that controls the adsorption of the five different coconut charcoals; and To determine the best charcoal to be used for adsorption.

The study was limited to characterizing the five charcoal samples given by the graduate student doing research about pyrolysis. The parameters for the characterization of the five charcoal samples in this study only involved Proximate Analysis, Methylene Blue Value and Adsorption Kinetic Study. The parameters (pressure, temperature, reaction time) concerning the production of the five charcoals were not discussed in this paper.

\section{MATERIALS AND METHODS}

\section{Preparation of Coconut Shell Charcoal}

Charcoals made of coconut shells were sampled from four different techniques of pyrolysis, namely: Drum Kiln Method; Pit or Earth Method; Top-Lift Updraft (TLUD) Method and Hookway Retort Method. Five samples were gathered and named based on the method used. For this study, the samples from the different methods were named as follows:

-Pag-Asa Kiln (1) for Drum Kiln method

- Supplier's Coal (2) for Pit method

-Top New (3) for the sample collected from the top part of the container of the TLUD method

-Bottom New (4) for the sample collected from the bottom part of the container of the TLUD method

-David's Reactor (5) for Hookway Retort method

The samples were pulverized using a mortar and pestle. The pulverized samples that passed through a $250 \mu \mathrm{m}$ (No. 60) Tyler sieve were stored in a clean and dry airtight container. 


\section{Characterization of charcoal produced from different Pyrolyzing}

\section{Proximate Analysis}

The proximate analysis measures the suitability of charcoal to be used for its application. For this study, charcoal is expected to be used for adsorption.

\section{Moisture Content Determination}

The moisture content of the different coconut charcoals used in the experiment was measured using the oven drying method in accordance with ASTM D3302, "Test Method for Total Moisture in Coal". The steps followed are shown in Figure 1.

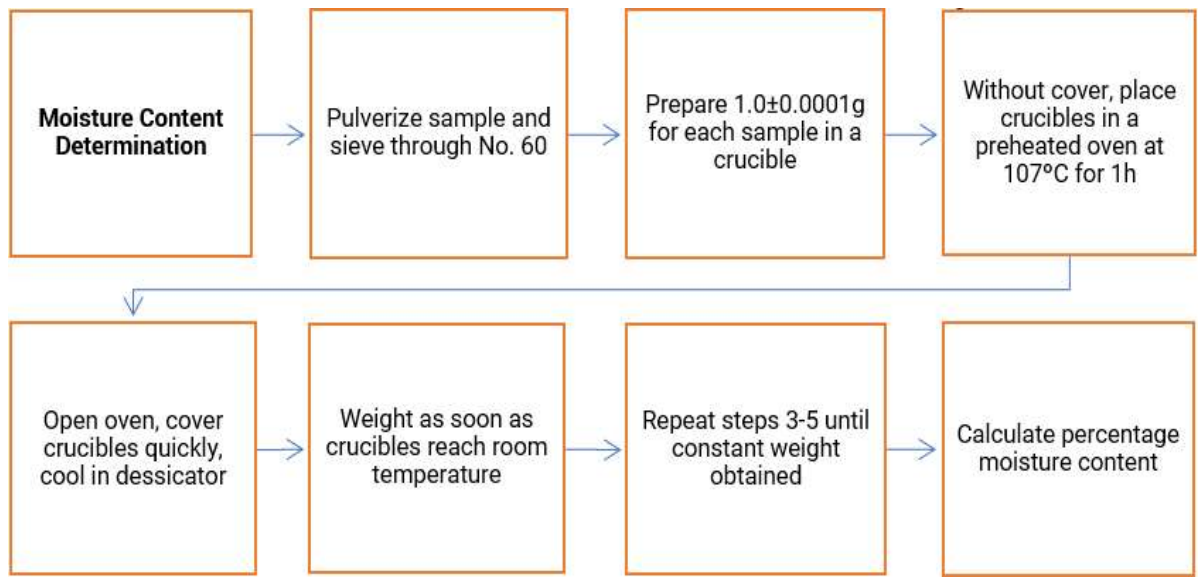

Figure 1. Flowchart of Moisture Content Determination in accordance with ASTM D3302

The moisture content of the samples was computed using the dry-weight basis using the formula given:

$$
M \mathbf{C}_{\mathrm{db}}=\frac{W_{0}-W_{d}}{W_{0}} \times 100
$$

where,

$$
\begin{aligned}
& M_{\mathrm{db}}=\text { moisture content dry-weight basis } \\
& W_{o}=\text { initial weight of the sample } \\
& W_{d} \quad=\text { final/oven-dry weight of the sample }
\end{aligned}
$$

\section{Volatile Matter Content Determination}

The volatile matter content of the different coconut charcoal was measured in accordance with ASTM D3175-17, which is the standard test method for volatile matter in the analysis sample of coal. The steps followed are shown in Figure 2. 


\section{Curay et al}

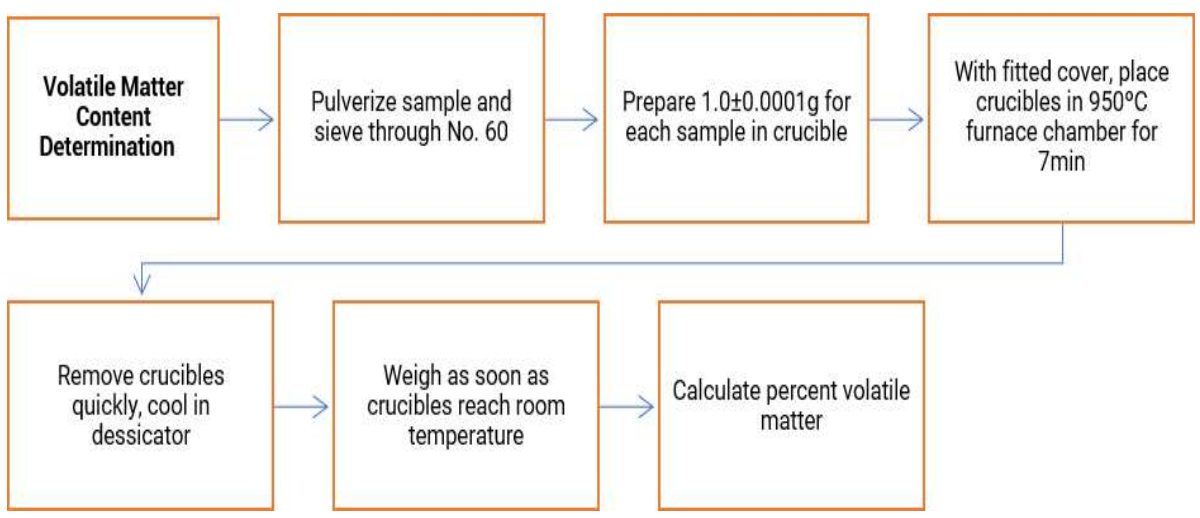

Figure 2 Flowchart of volatile matter determination in accordance with ASTM D3175-17

The volatile matter content of the samples were computed based on the formula:

where,

$$
V_{d}=100 \times \frac{100(B-F)-M_{c}(B-G)}{(B-G)\left(100-M_{c}\right)}
$$

B = mass in $\mathrm{g}$ of the crucible, lid, and sample before heating

$F=$ mass in $g$ of the crucible, lid, and contents after heating

$\mathbf{G}=$ mass in $\mathbf{g}$ of the empty crucible and lid

$M_{c}=$ moisture, as a percentage by mass.

$V_{d}=$ volatile matter content; $\%$

\section{Ash Content Determination}

The ash content of the different coconut charcoals used in the experiment was measured in accordance with ASTM D3174-12, the standard method used in the "Test Method for Ash in the Analysis Sample of Coal". Figure 3 shows the summarized flowchart of the method.

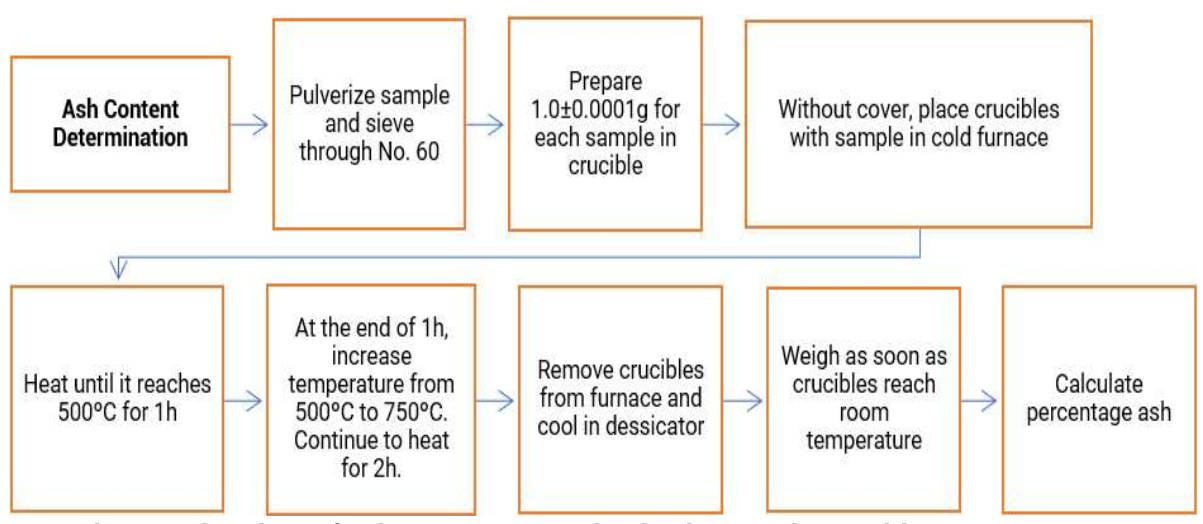

Figure 3 Flowchart of Ash Content Determination in accordance with ASTM D3174-12 


\section{Characterization of charcoal produced from different Pyrolyzing}

The ash content of the samples was computed based on the formula:

$$
A_{c}=100 \times \frac{F-G}{B-G}
$$

where,

$$
\begin{aligned}
& \mathbf{G}=\text { mass of the empty crucible in grams; } g \\
& B=\text { mass of crucible plus dried sample in grams; } g \\
& F=\text { mass of crucible plus ashed sample in grams, } g \\
& A_{c}=\text { ash content; } \%
\end{aligned}
$$

\section{Fixed Carbon Determination}

According to ASTM D3172-13, which is the Standard Practice for Proximate Analysis of Coal, fixed carbon content is the resultant of the summation of percentage moisture, ash, and volatile matter subtracted from 100 . The fixed carbon content of the samples was computed using the formula:

$$
F_{c}=100-\left(M C_{d b}+A_{c}+V_{d}\right)
$$

where,

$$
\begin{aligned}
& M C_{d b}=\text { moisture content dry-weight basis; } \% \\
& A_{c}=\text { ash content; } \% \\
& V_{d}=\text { volatile matter content; } \% \\
& F_{c} \quad=\text { fixed carbon content; } \%
\end{aligned}
$$

\section{Design and Optimization}

The charcoal sample from David's Reactor was used to determine the optimal value for the adsorption parameters, namely, the initial Methylene Blue (MB) concentration, adsorbent dose, and $\mathrm{pH}$ of a solution. The optimal values found in this experiment were applied for the adsorption kinetic study of all the other charcoal samples. The adsorption parameters were examined using the BoxBehnken design.

\section{Batch Adsorption Experiment}

Batch experiments were carried out for David's Reactor charcoal in Erlenmeyer flasks with $50 \mathrm{~mL}$ dye solution agitated using a gyratory shaker at 300rpm setting. Experiments were performed under varying initial MB concentration (30-150ppm), adsorbent dose (1.0-2.0g), and $\mathrm{pH}(2-4)$. The treated solution was then filtered, and the sample absorbance was calculated using the formula:

$$
\text { \%removal }=\left(\frac{C_{0}-C_{e}}{C_{0}}\right) \times 100
$$

where $\mathrm{C}_{0}$ and $\mathrm{C}_{\mathrm{e}}$ are the initial and final concentrations in ppm, respectively. 


\section{Kinetic Studies}

The kinetic study was carried out using David's Reactor sample's optimum level of $74 \mathrm{ppm}$ for initial MB concentration, $1.7 \mathrm{~g}$ for adsorbent dose, and 2.73 reading for $\mathrm{pH}$. These conditions were applied to all of the five (5) samples. Each sample of $50 \mathrm{~mL}$ dye solution was agitated in a shaker at $300 \mathrm{rpm}$. The samples were then collected at an interval of every $10 \mathrm{~min}$ for $60 \mathrm{~min}$. After filtration, the final concentration was analyzed using UV-Vis, and the adsorption capacity is computed using the equation:

$$
\begin{aligned}
q_{e} & =\frac{\left(C_{o}-C_{e}\right) \times V}{M} \\
\text { Where; } & \\
V & =\text { volume of the dye solution, } \mathrm{mL} \\
M & =\text { mass of the adsorbent, } g
\end{aligned}
$$

\section{Weighting and Ranking}

The weights of the criteria were based on their relevance to determine the best coconut charcoal sample for adsorption purposes. The criteria considered in this study, together with their corresponding weights, are shown in table 1 below.

Table 1. Criteria and corresponding weights for ranking charcoal samples

\begin{tabular}{cc}
\hline Criteria & \\
\hline Adsorption Capacity & $70 \%$ \\
Fixed Carbon & $20 \%$ \\
Volatile Matter & $10 \%$ \\
\hline
\end{tabular}

For adsorption capacity and fixed carbon, the obtained results were directly multiplied to its corresponding weight. For volatile matter, the sum of all the results was subtracted to each of the results for each product and divided afterward. The obtained dividends were then multiplied by the weight of the volatile matter. The weighted results of the three criteria for each pyrolyzed product were summed. The ranking was done from greatest to least. The most desirable charcoal product for adsorption purposes was the product having the greatest value.

\section{RESULTS AND DISCUSSION}

\section{Characterization based on Proximate Analysis}

\section{Moisture content}

Moisture content is the ratio of the mass of water to the mass of solids in the sample. Moisture content is significant to know since water, which is polar in nature, takes up space in the charcoal's structure. The presence of water, therefore, makes the charcoal less effective for adsorption. Based on Figure 4 shown below, the supplier's charcoal sample had the lowest moisture content, while the sample from David's Reactor had the highest observed value. Samples from Pag-Asa Kiln and Top-New had moisture content in close proportion. 


\section{Characterization of charcoal produced from different Pyrolyzing}

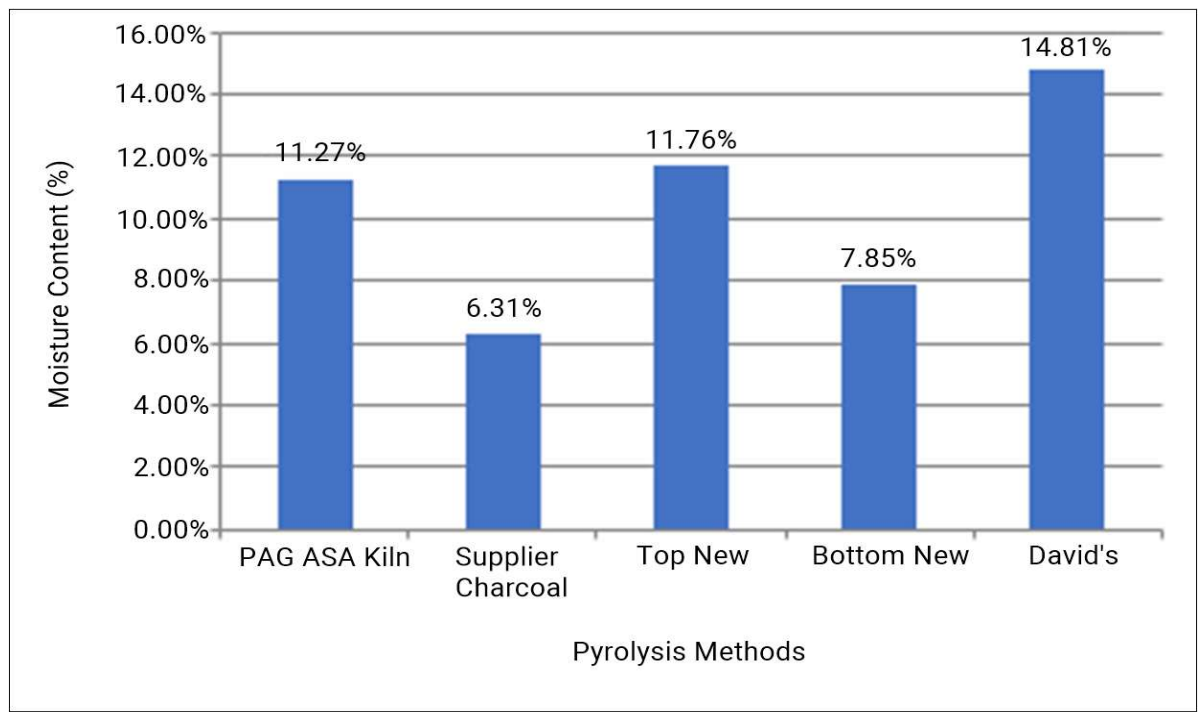

Figure 4. Moisture Content of five different charcoal samples

\section{Volatile Matter}

Volatile matter content is an important determination for evaluating charcoal's combustion characteristics. It can vary from a high of Volatile matter is usually specified free of moisture content. Generally, charcoal with high volatile-matter content ignites more easily than that with low volatile matter and is highly reactive in combustion applications. Highly volatile charcoal is preferable for some purposes, such as barbecuing, while other uses need charcoal with low percentages of volatile matter content, such as chemical purification and metal manufacturing. In general, for adsorption purposes, the high volatile matter is not favorable because of its unstable nature that changes to another state or vaporizes. Once a part of the charcoal vaporizes, the surface for adsorption decreases, making it less effective for that purpose.

Figure 5 shows that all the samples have volatile matter content within the expected range for charcoals. The percentage of volatile matter in charcoal from the bottom part of the top-lift updraft (TLUD) technique presented the highest proportion compared to others at $43.39 \%$. Charcoal produced by drum kiln and pit method had close values of percentage of volatile matter proportions at $30.69 \%$ and $31.65 \%$, respectively. The sample from David's Reactor had a volatile matter percentage of $24.13 \%$, while the top part of the TLUD method had the lowest value at $20.65 \%$. Highly volatile charcoal is easy to ignite but may burn with a smoky flame, compared to charcoal with low volatility that may be harder to ignite but burns very cleanly. Having higher volatile matter content produces less fines during transport and handling. 
Curay et al

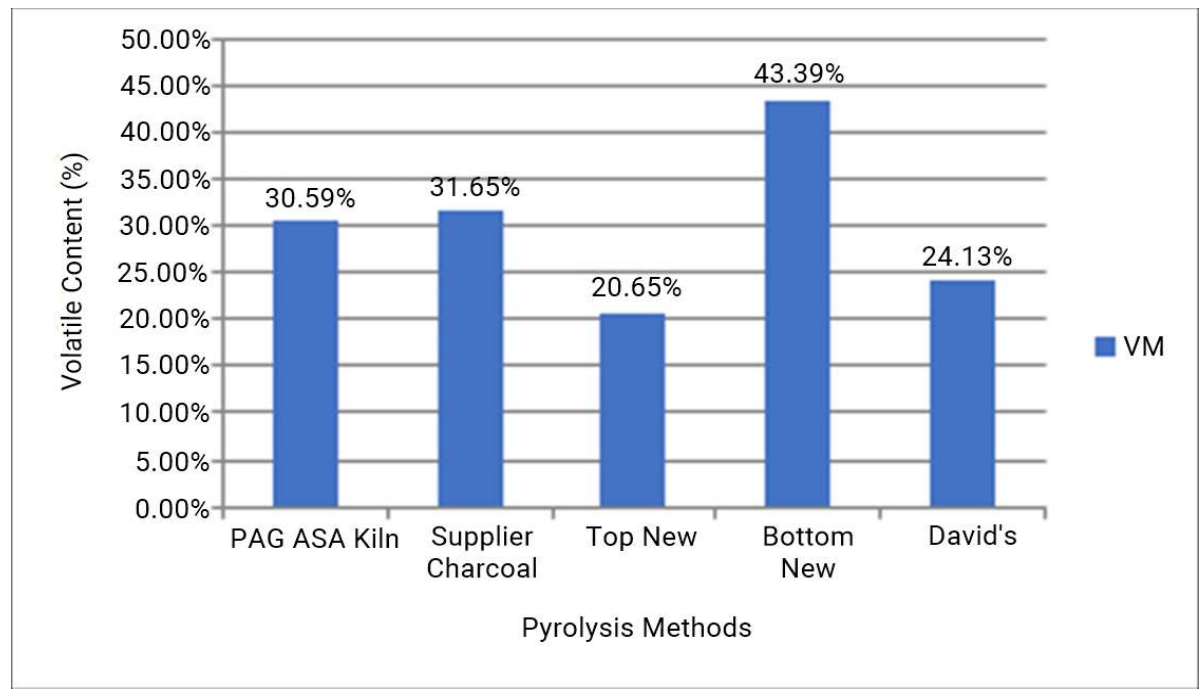

Figure 5. Volatile matter of five different charcoal samples

\section{Ash Content}

Ash content measures the residue remaining after burning all the combustible matter of the sample. It is said that ash content reduces the overall activity of activated carbon and its efficiency of reactivation (Carbochem). Applying this statement to ordinary charcoal, ash may reduce the adsorption capacity of charcoal.

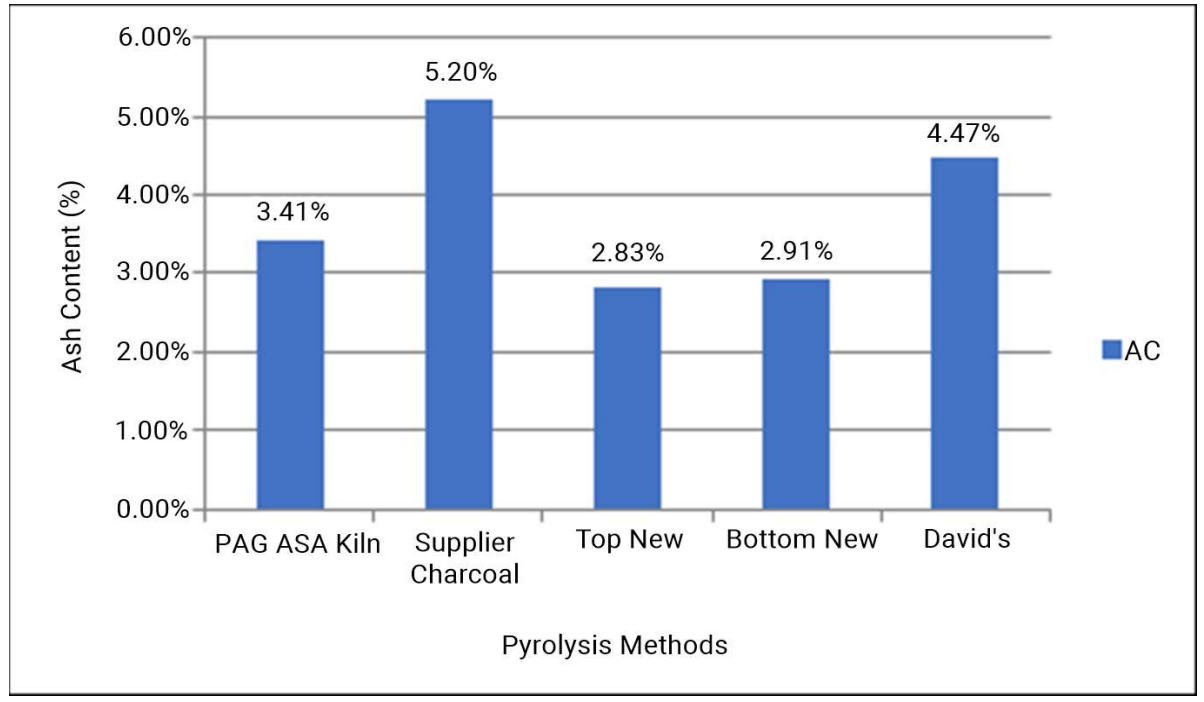

Figure 6. Ash Content of five different charcoal samples 


\section{Characterization of charcoal produced from different Pyrolyzing}

\section{Fixed Carbon}

The fixed carbon content of charcoal ranges from a low of about $50 \%$ to a high of around $95 \%$, suggesting that charcoal consists mainly of carbon. Based on the graph below, it can be observed that all samples aside from the charcoal from the bottom part of the TLUD method are within the range expected for charcoals. The greatest proportion of fixed carbon can be observed on the charcoal from the top part of the TLUD method. The samples produced from the drum kiln, pit method, and hookway retort method have a close values for percentage fixed carbon proportions of $54.63 \%, 56.84 \%$, and $56.59 \%$, respectively. Charcoal from the bottom part of the TLUD method had the lowest percentage of $45.85 \%$. A higher fixedcarbon content indicates that the charcoal will exhibit a longer combustion time.

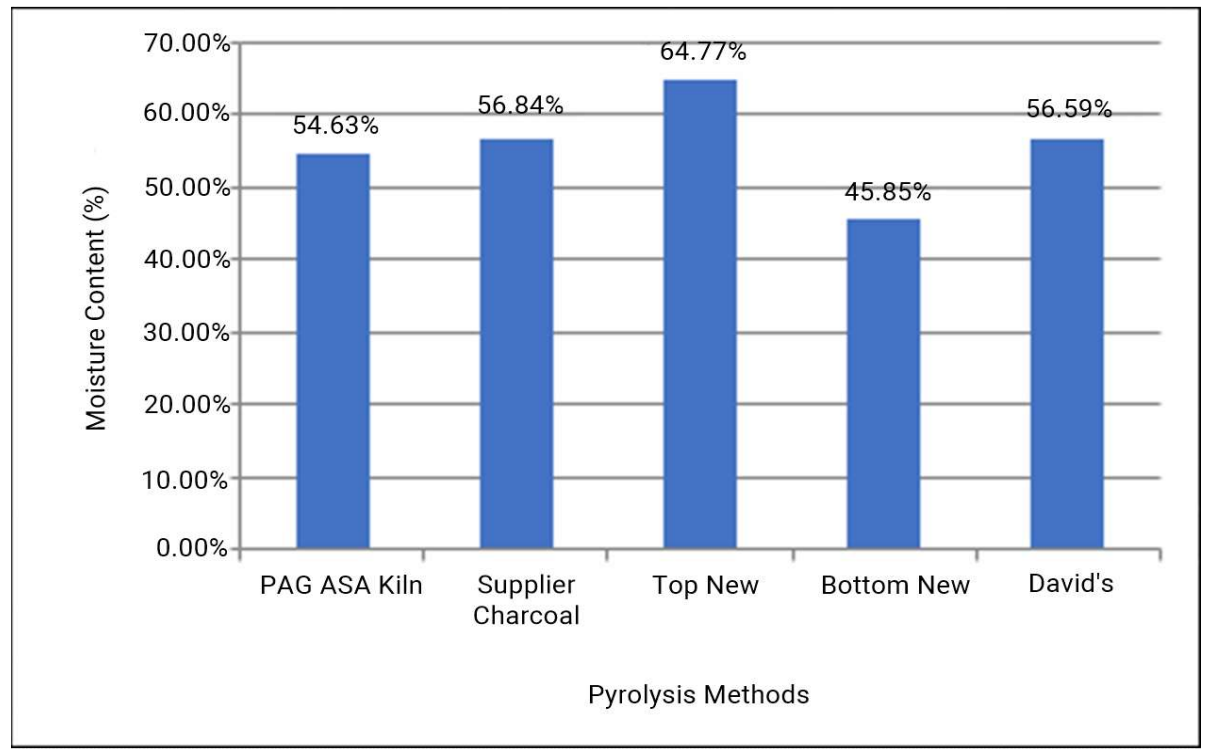

Figure 8. Fixed Carbon Content of five different charcoal samples

\section{Optimization of Adsorption Parameters}

The table below lists the summary of the analysis of variance results using the quadratic model, which best fitted the data points in the experiment with the coefficient of determination of $\mathrm{R}^{2}=0.9585$.

The Model F-value of 31.82, according to Design Expert, implies a significant model. The P-Value Probability $>\mathrm{F}$ less than 0.0500 indicates model terms are significant. The lack of fit F-value of 0.32 implies that it is not significant relative to the pure error.

The figure 12 below shows a plot of the actual vs predicted values of the charcoal sample's percentage removal of MB. The graph shows that the points are near the line. 
Curay et al

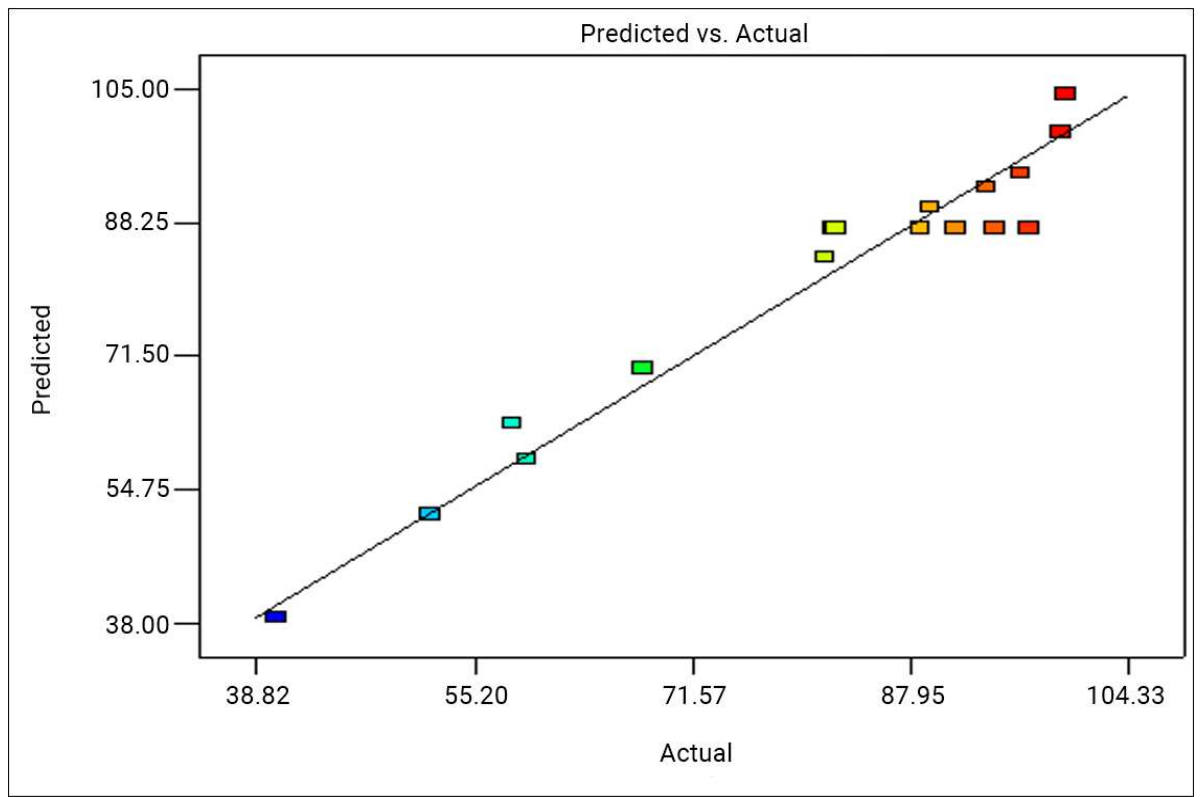

Figure 12. A plot of Predicted versus Actual Values of Charcoal Sample's Percent Removal

The optimum conditions found are the following: 74ppm for Initial Methylene Blue Concentration, $1.7 \mathrm{~g}$ for Adsorbent Dose, and 2.73 for $\mathrm{pH}$. The graph below shows the optimal concentration and adsorbent dose value at $2.73 \mathrm{pH}$ at $97.5069 \%$ predicted removal. Due to limited available charcoal samples, a confirmatory experiment was not done.

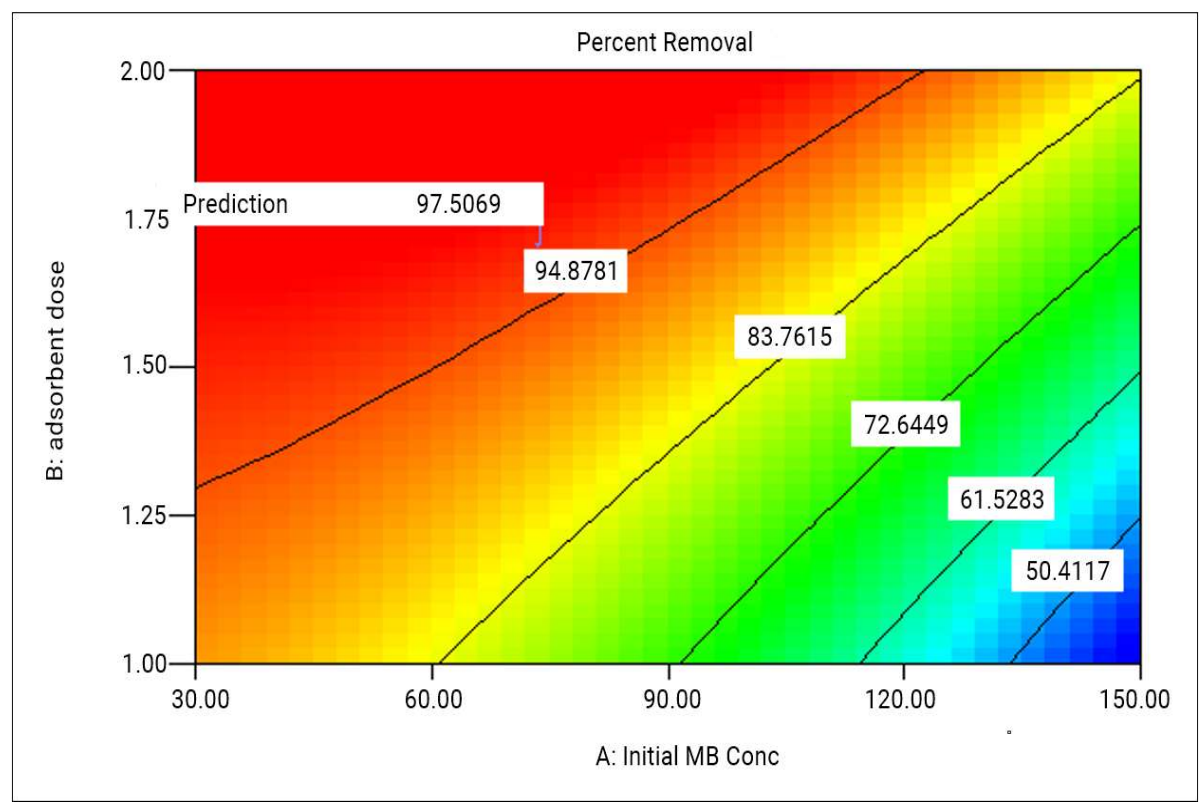

Figure 13. Effect of Initial MB Concentration (ppm) on Percent Removal of Charcoal Sample 


\section{Characterization of charcoal produced from different Pyrolyzing}

\section{Effect of Initial Concentration}

The effect of initial MB concentration on percentage removal at $1.5 \mathrm{~g}$ adsorbent dose of charcoal is shown in the graph below. At lower MB concentrations, percentage removal is high. At higher $\mathrm{MB}$ concentrations, percentage removal is lower. The relationship between initial concentration and percentage removal is, therefore, inversely proportional. A similar trend had been found in the study of de Luna et al (2013) on the adsorption of Eriochrome Black T dye using rice hull activated carbon.

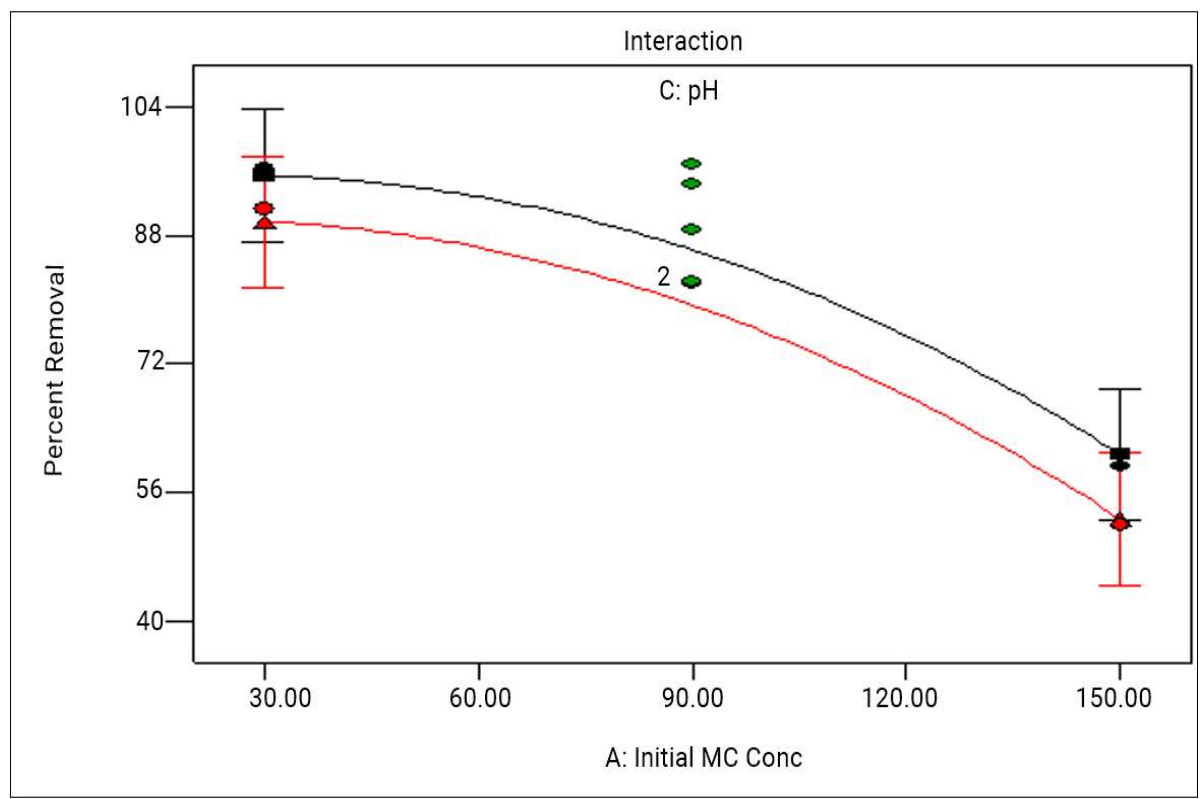

Figure 14. Effect of Initial MB Concentration (ppm) on Charcoal Sample's Percent Removal

\section{Effect of Adsorbent Dose}

The effect of the adsorbent dose of the charcoal sample on the percentage removal of the $M B$ is shown in the figure 15 below. The percentage removal increased as the adsorbent dose increased from 1.0 to $2.0 \mathrm{~g}$. Therefore, an increase in the number of available adsorption sites gives an increase of $\mathrm{MB}$ dye adsorbed because more surface area is available for adsorption.

A positive correlation is seen in the graph of the percentage removal versus the adsorbent dose. This has the same result as the study of de Luna et al (2013) on the adsorption of Eriochrome Black T dye using rice hull activated carbon.

\section{Effect of pH}

From the two previous graphs, it can be seen that percentage removal decreased as the $\mathrm{pH}$ of the solution increased. This phenomenon may be due to the fact that as the solution becomes more acidic, the functional groups in the charcoal 
sample become more positively charged or protonated, which causes the MB dye to become more electro-statically attracted to the adsorbent. At a lower $\mathrm{pH}$, the adsorption is increased.

\section{Adsorption Kinetic Studies}

In the adsorption studies, the efficiency of adsorption is expressed as q, which is the amount of adsorbate adsorbed per amount of adsorbent used for adsorption.

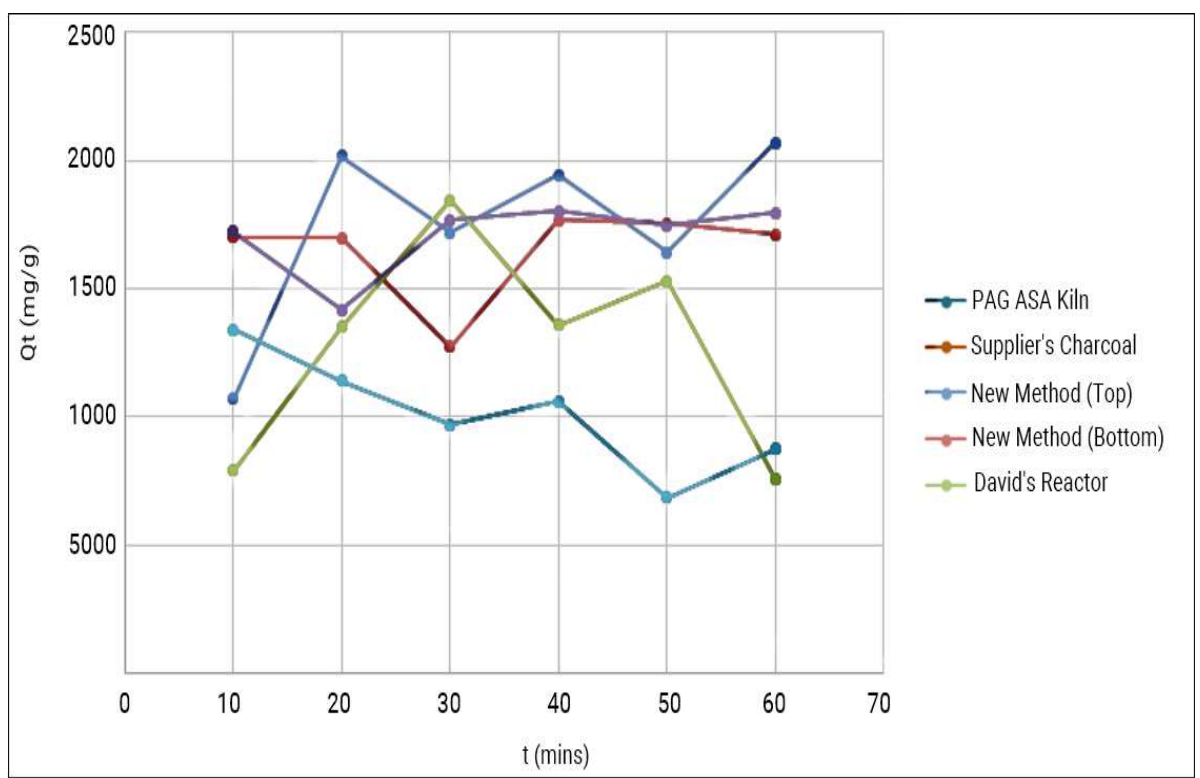

Figure 16. Adsorption Capacity vs. Time

The figure 16 above shows the graph of adsorption capacity versus time. Based on the data plotted, the charcoal from PAG-ASA Kiln showed the highest adsorption efficiency while David's Reactor gave the lowest.

For this study, two kinetic models were used to identify the adsorption mechanism exhibited in the experiments. The kinetic models used were the pseudo-first-order mechanism and the pseudo-second-order mechanism.

Adsorption data of the five samples, each with six readings for one hour with 10 min intervals, were fitted in the kinetic model equation. Pseudo-first order model is given with the equation below:

$$
\log \left(q_{e}-q_{t}\right)=\log q_{e}-\frac{k_{1}}{2.303} t
$$


Characterization of charcoal produced from different Pyrolyzing

where,

$\mathrm{q}_{\mathrm{e}}=$ equilibrium adsorption capacity; $\mathrm{mg} \mathrm{g}^{-1}$

$\mathbf{q}_{\mathrm{t}}=$ adsorption capacity at time $\mathrm{t} ; \mathrm{mg} \mathrm{g}^{-1}$

$\mathrm{k}_{\mathbf{1}}=$ pseudo-first-order rate constant; $\mathrm{min}^{-1}$

$\mathrm{t}=$ time; $\min$

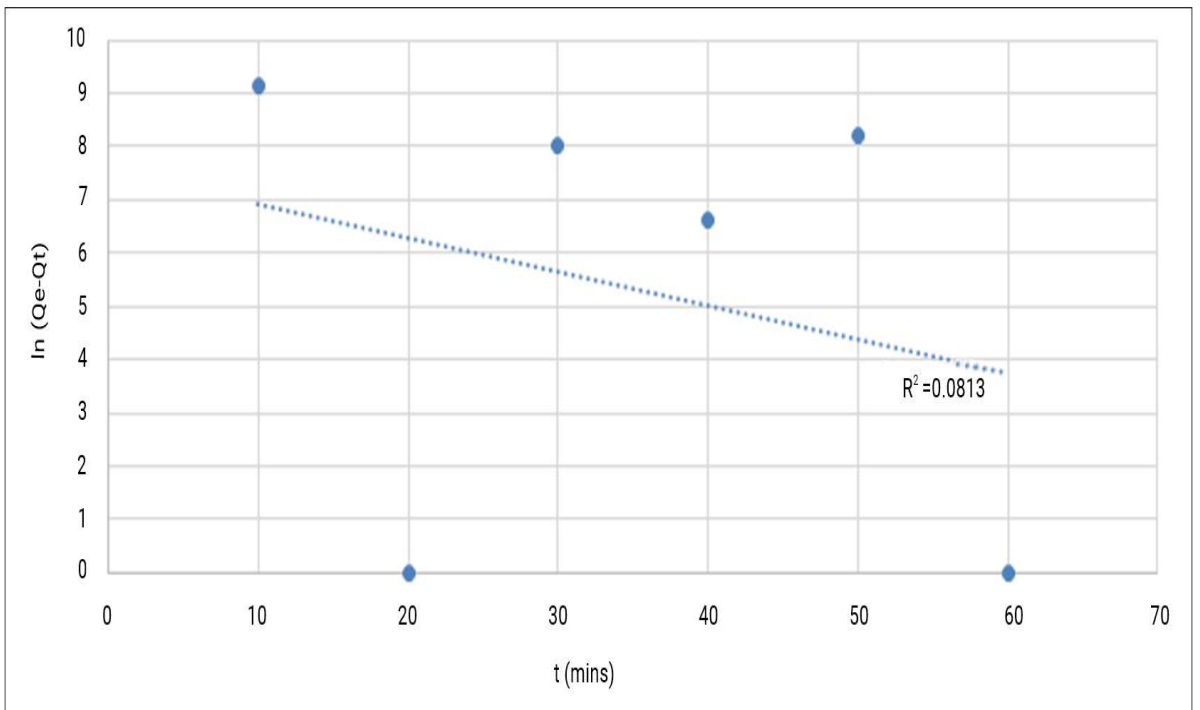

Figure 17. Pseudo-first order kinetics - PAG ASA Kiln

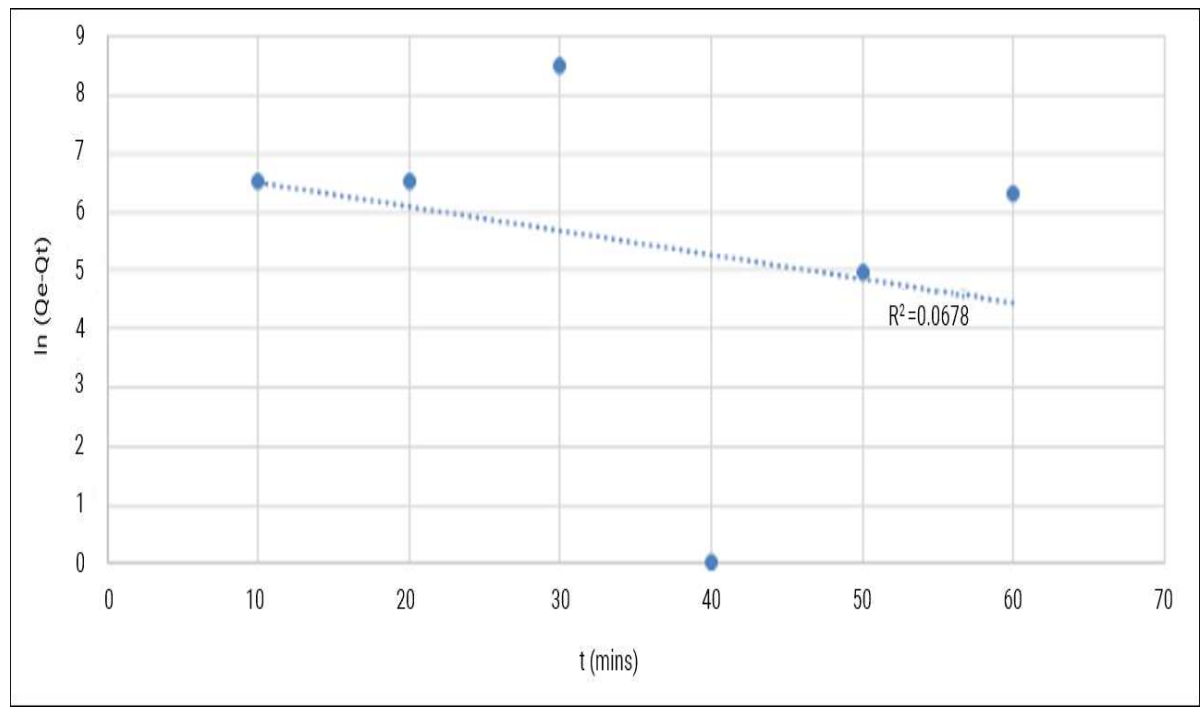

Figure 18. Pseudo-first order kinetics - Supplier's Charcoal 


\section{Curay et al}

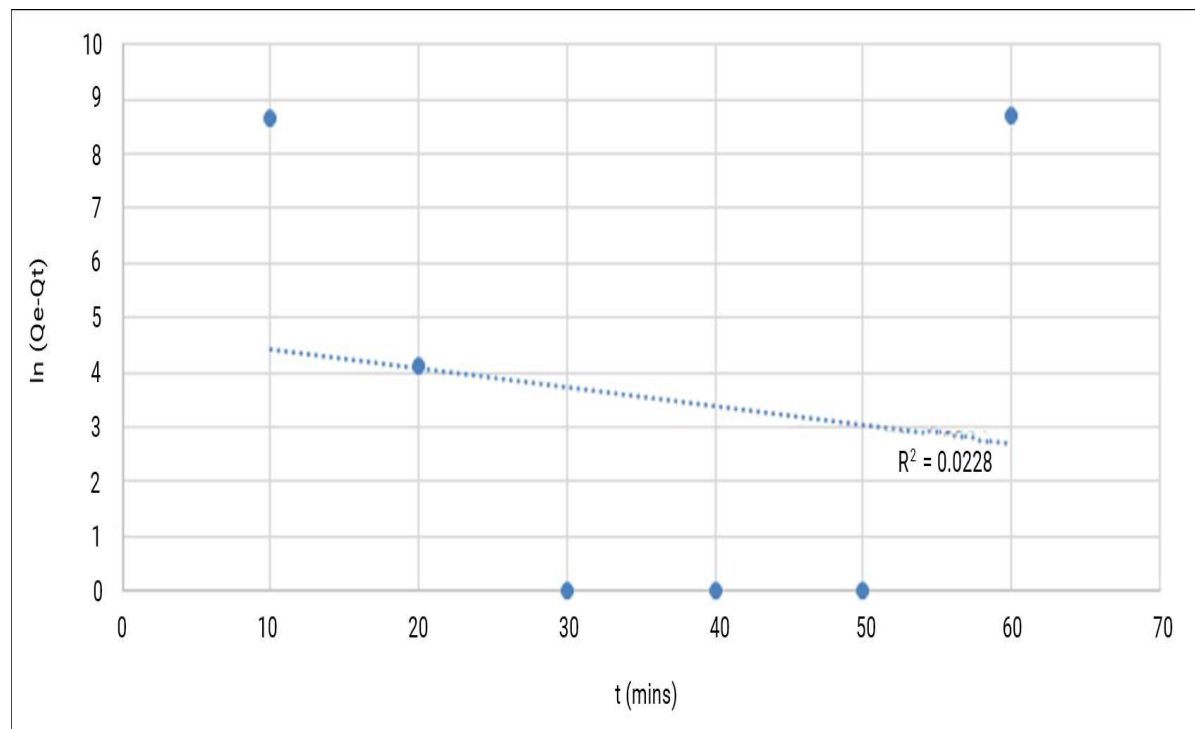

Figure 19. Pseudo-first order kinetics - New Method (Top)

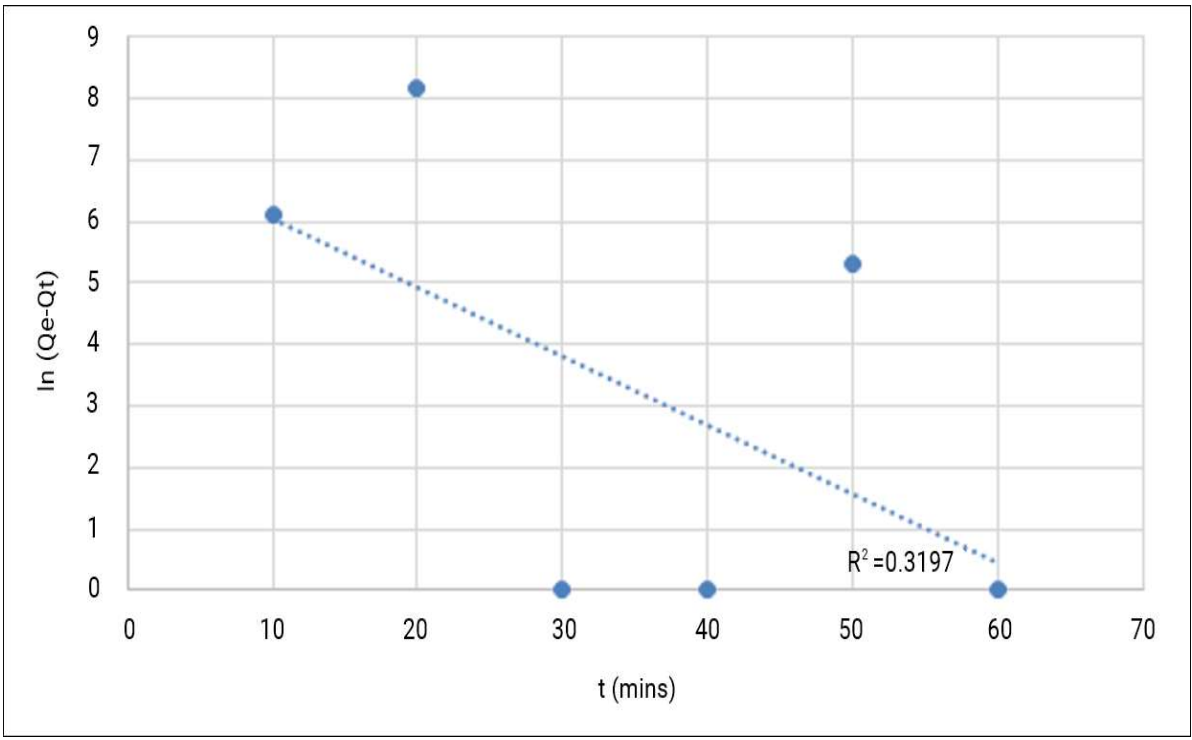

Figure 20. Pseudo-first order kinetics - New Method (Bottom) 


\section{Characterization of charcoal produced from different Pyrolyzing}

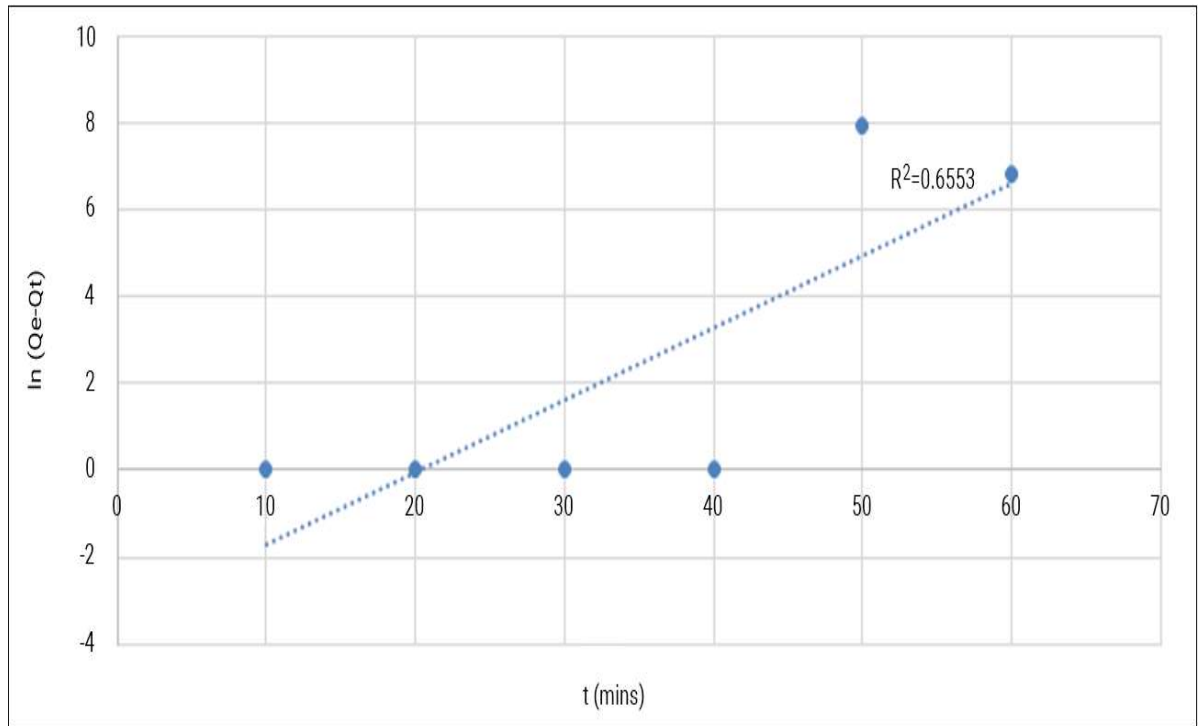

Figure 21. Pseudo-first order kinetics - David's Reactor

Figures show that there is a low correlation using the pseudo-first-order kinetic model. Hence, the pseudo-second-order was used given the equation below:

$$
\frac{t}{q_{t}}=\frac{1}{k_{2} q_{e}^{2}}+\frac{1}{q_{e}} t
$$

where,

$k_{2}=$ rate of constant of pseudo-second-order adsorption; $\mathbf{~ g ~ m g}^{-1} \mathbf{~ m i n}$

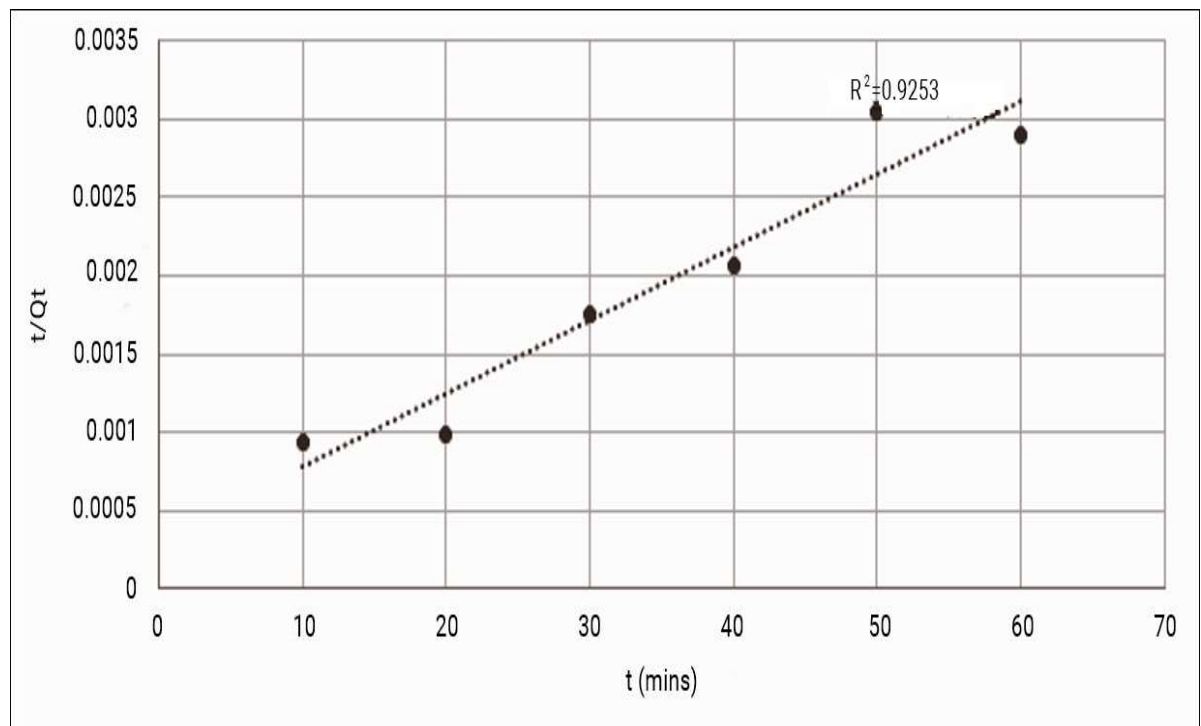

Figure 21. Pseudo-second order kinetics - PAG ASA Kiln 


\section{Curay et al}

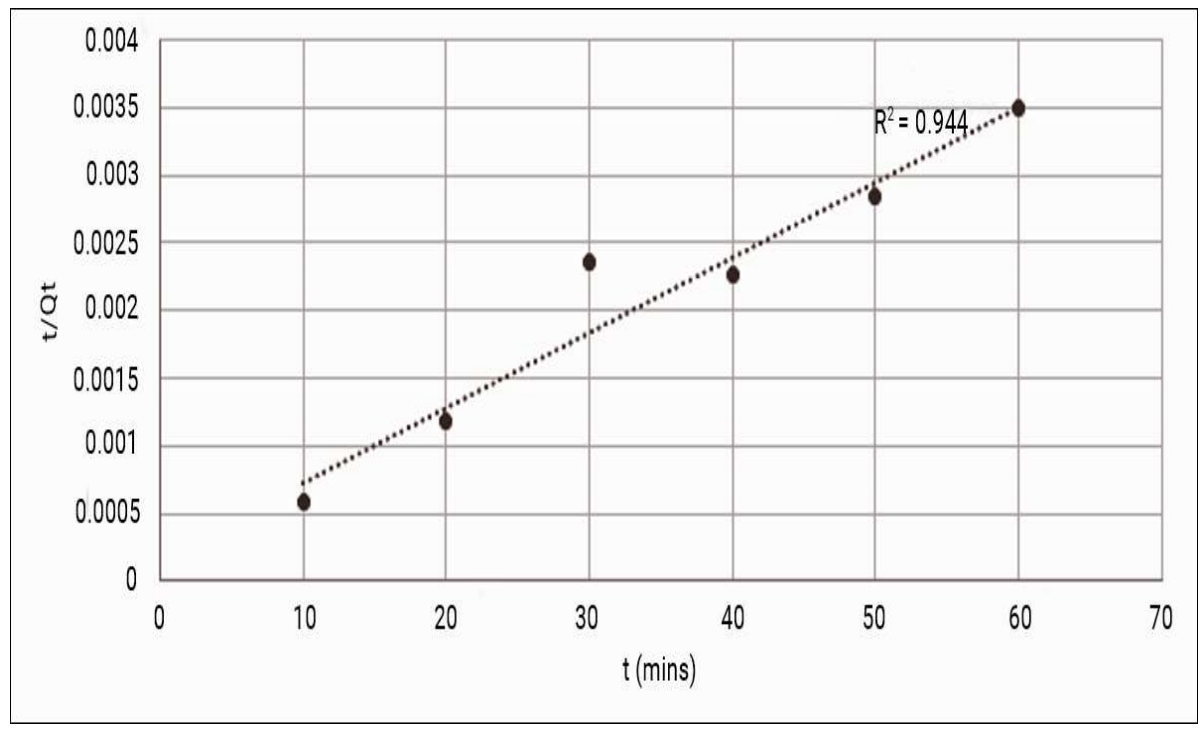

Figure 21. Pseudo-second order kinetics - Supplier's Charcoal

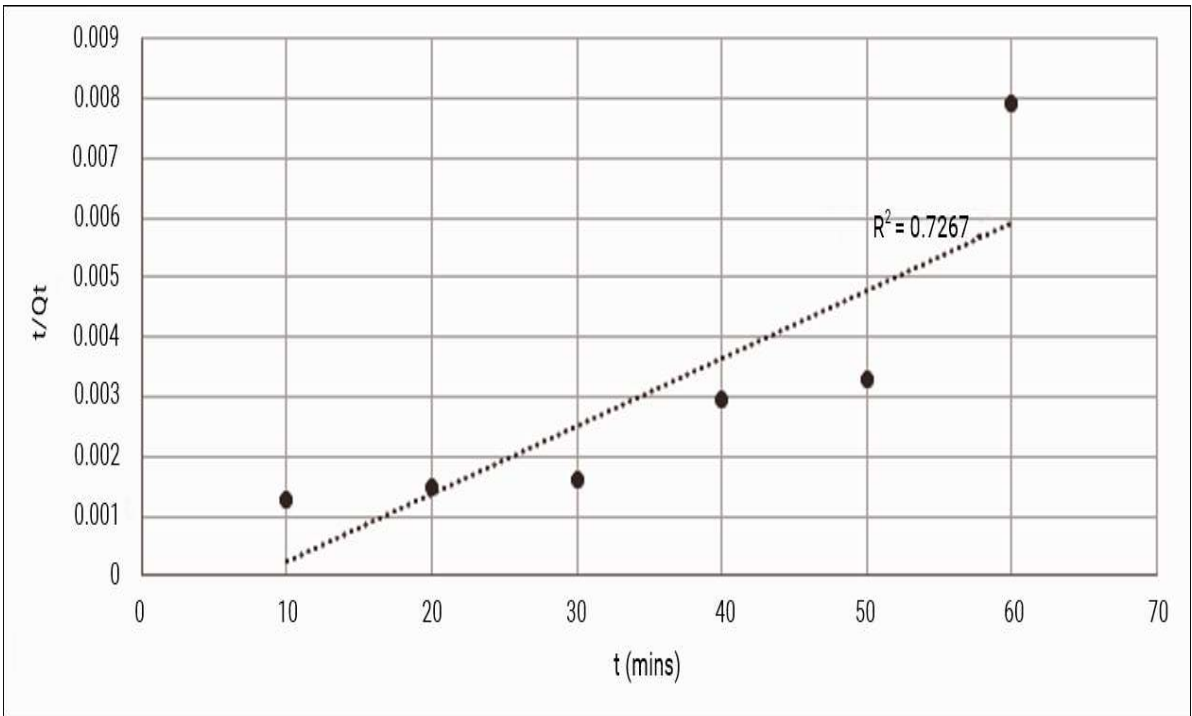

Figure 21. Pseudo-second order kinetics - New Method (Top) 


\section{Characterization of charcoal produced from different Pyrolyzing}

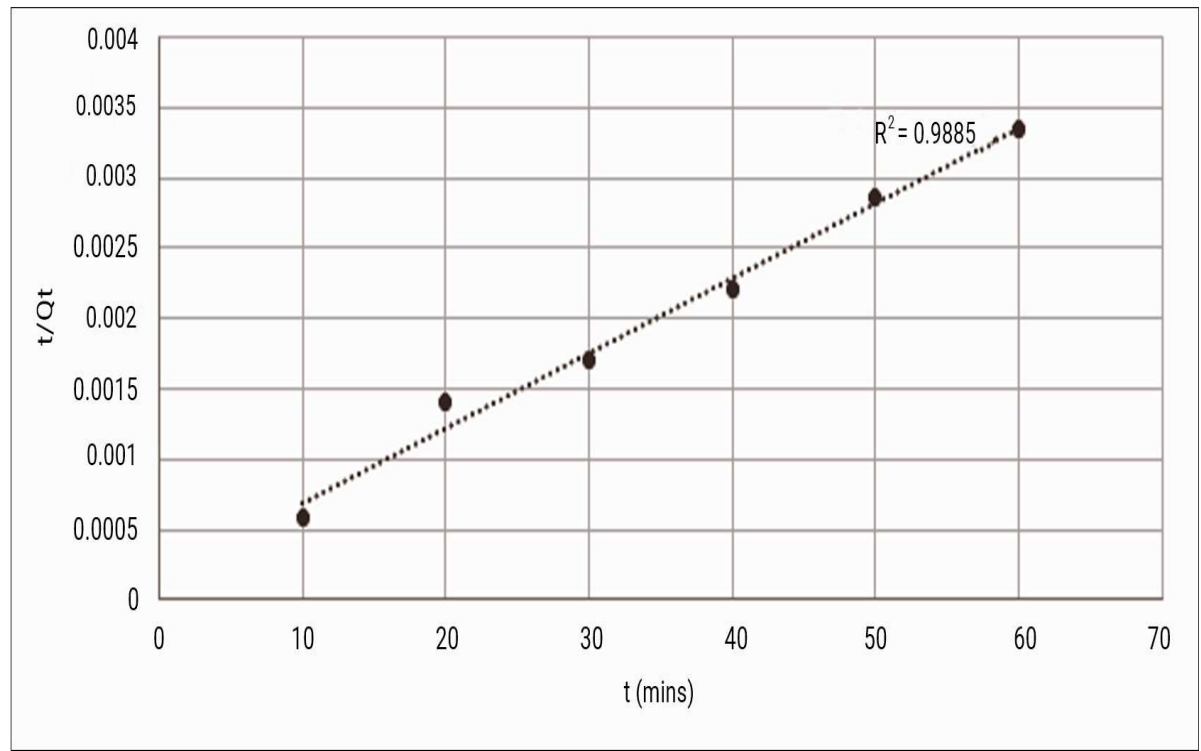

Figure 21. Pseudo-second order kinetics - New Method (Bottom)

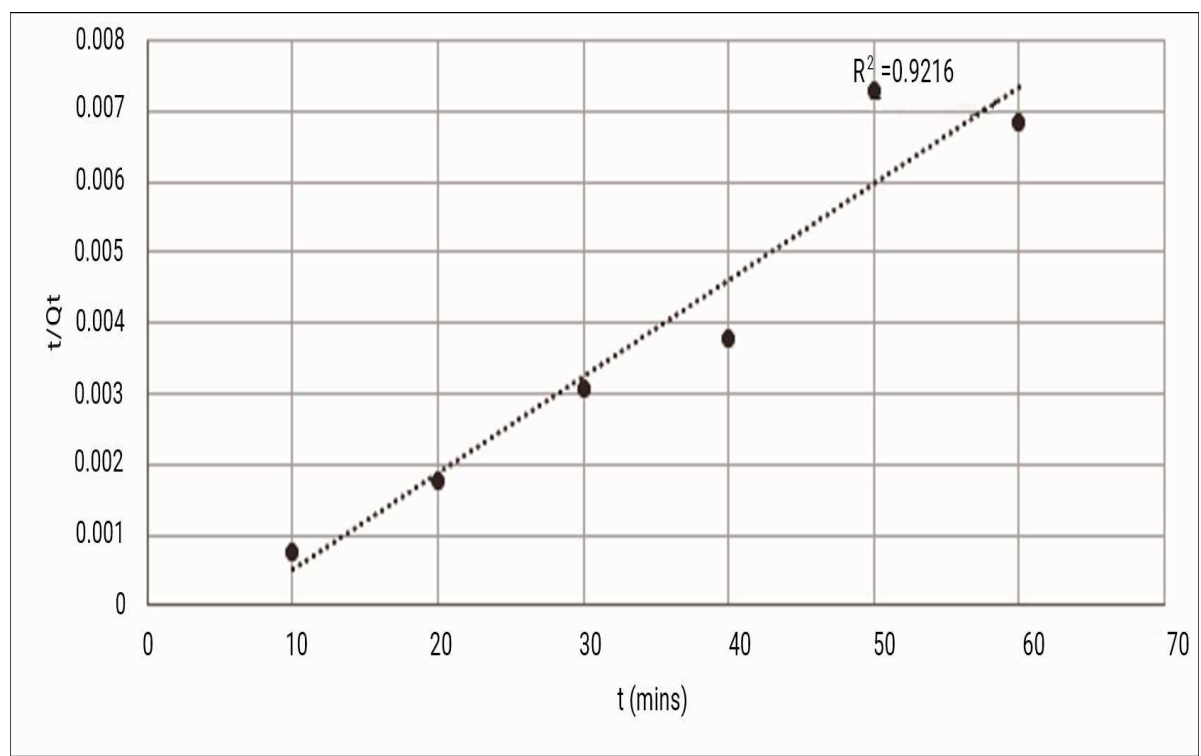

Figure 21. Pseudo-second order kinetics - David's Reactor

Based on the figures shown, the adsorption follows a pseudo-second-order mechanism, which indicates that chemisorption is the rate-determining step. 


\section{Weighting and Ranking}

Incorporating all the results from the proximate analysis and adsorption kinetic study and applying the weights of the criteria, the best charcoal sample is from Kiln, followed by Pit, TLUD-Bottom, TLUD-Top, and Hookway retort. It appears that the most efficient pyrolyzing technique in this study has the charcoal product, which exhibits the least capability to be used for adsorption purposes.

\section{CONCLUSION AND RECOMMENDATION}

Based on the weight given for each of the measured parameters with respect to their significance on the adsorptive capacity of the charcoal samples, the ranking of the methods are as follows: Kiln, Pit, Top-Bottom, Top New, and David's Reactor.

It is recommended to employ Fourier Transform Infrared Spectroscopy to be able to identify organic, inorganic, polymeric, and chemical properties of the samples. Furthermore, Brunauer-Emmett-Teller Analysis can also be used to know the specific surface area of the samples.

Pressure, humidity, and temperature during pyrolyzing could also be incorporated into the study to determine how these parameters affect the quality of the charcoal product.

For the adsorption study, the effect of solution temperature could be considered. Activation of the charcoal samples could also be considered for future studies.

\section{REFERENCES}

Aljeboree AM, Alshirifi AN \& Alkaim AF. 2014. Kinetics and equilibrium study for the adsorption of textile dyes on coconut shell activated carbon. Arabian Journal of Chemistry 10(Supplement 2):S3381-S3393

ASTM Standard D3172-13. 2013. Standard Practice for Proximate Analysis of Coal and Coke. ASTM International, West Conshohocken, Pennsylvania, USA

ASTM Standard D3174-12. 2012. Standard Test Method for Ash in the Analysis Sample of Coal and Coke. ASTM International, West Conshohocken, Pennsylvania, USA

ASTM Standard D3175-17. 2017. Standard Test Method for Volatile Matter in the Analysis Sample of Coal and Coke, ASTM International, West Conshohocken, Pennsylvania, USA

ASTM Standard D3302. 2017. Standard Test Method for Total Moisture in Coal, ASTM International, West Conshohocken, Pennsylvania, USA

De Luna MG, Flores, ED, Genuino DD, Futalan CM \& Wan MW. 2013. Adsorption of Eriochrome Black T (EBT) dye using activated carbon prepared from waste rice hulls-Optimization, isotherm, and kinetic studies. Journal of the Taiwan Institute of Chemical Engineers 44:646-653

Feng Y, Yan W \& Chu W. 2014. Contribution of Ash Content Related to Methane Adsorption Behaviors of Bituminous Coals. International Journal of Chemical Engineering (pp1-12) 